\title{
GEODYNAMICS OF THE INDIAN LITHOSPHERIC PLATE RELATIVE TO THE NEIGHBOURING PLATES AS REVEALED BY SPACE GEODETIC MEASUREMENTS
}

\author{
Siva Krishna ${ }^{*}$, John Mathew, Ritwik Majumdar, Priyom Roy and K. Vinod Kumar \\ National Remote Sensing Centre, Indian Space Research Organization (ISRO), \\ Balanagar, Hyderabad, India. PIN 500037. \\ sivakrishna.isro@gmail.com,(john_mathew,ritwik_m, priyom_roy, vinodkumar_k)@nrsc.gov.in
}

KEY WORDS: Geodynamics, Geodesy, Himalaya, Gamit/Globk, Pole of rotation, Indian plate

\begin{abstract}
:
The Indian Plate is highly dynamic in nature which in turn makes the Indo-Eurassian collision zone the foci of most of the historic large magnitude earthquakes. Processing of positional information from continuously observing reference stations is one of the space based geodetic techniques used globally and nationally to understand the crustal dynamics. The present study evaluates the dynamic nature of the Indian plate relative to its adjoining plates using the permanent GPS data (2011 to 2013) of 12 International GNSS Service (IGS), which are spread across the Indian, Eurassian, Australian, Somaliyan and African plates. The data processing was carried out using GAMIT/GLOBK software. The results indicate that the average velocity for the two IGS stations on the Indian Plate (Hyderabad and Bangalore) is $54.25 \mathrm{~mm} /$ year towards NE in the ITRF-2008 reference frame. The relative velocity of various stations with respect to the Indian plate has been estimated using the Bangalore station and has been found that the stations in the Eurasian plate (Lhasa, Urumqi, Bishkek and Kitab) are moving with velocity ranging from 25 to $33 \mathrm{~mm} / \mathrm{year}$ in the SE direction resulting in compressional interaction with the Indian plate. This study reveals and confirms to the previous studies that the IndianEurassian-Australian Plates are moving at different relative velocities leading to compressional regimes at their margins leading to seismicity in these zones.
\end{abstract}

\section{INTRODUCTION}

Geodynamics studies about the movement and deformation of the earth's lithospheric plates and is caused by various forces from inside or outside of the earth. (Bevis and Gross, 2011). It is the root cause of plate tectonics resulting in crustal deformation and associated disasters. There are two types of geodetic techniques available for monitoring the geodynamics; ground based and space based. Both these methods have their own advantages and limitations. Triangulation, trilateration, electronic distance measurement, differential levelling, astronomical positioning and barometric levelling are some of the ground based geodetic techniques. Satellite/Lunar Laser Ranging (SLR/LLR), Global Navigation Satellite System (for example GPS, GLONASS, COMPASS, GALILEO etc.), Very Long Baseline Interferometry (VLBI), Doppler Orbitography and Radio Positioning Integrated by Satellite (DORIS) are the important space based geodetic techniques. The space geodetic techniques help to study the deformation of the earth and its motion as a finite body in the inertial reference system by deriving relevant information which include those about the transformation between the terrestrial and the inertial systems (Beutler 2005).This, in addition to the accuracy achievable in space geodesy makes it an important technique in the geodynamic studies.

In this ${ }^{1}$ study, GPS based geodesy, which is one of the important techniques using Global Navigation Satellite System (GNSS), is attempted to study the geodynamics of Indian and its adjoining plates. GPS geodesy has been used by many agencies and

\footnotetext{
* Corresponding author
}

researchers globally and in India also, to study the motion and deformation of crustal plates. Many Institutions have established their own GPS networks like those under the Department of science and technology (DST) and Ministry of Earth Sciences. These studies use permanent GPS sites (continuously observing reference stations, CORS) as well as campaign mode surveys. The CORS established under the International GNSS Service (IGS) stations also provide valuable input for geodynamic understanding of the region. IGS, formerly known as International GPS service, a voluntary federation of USA which contains more than 200 worldwide agencies in over 80 countries that gives the permanent GPS and GLONASS station data to generate precise GPS and GLONASS products. It provides the high quality of GNSS data and products which support the terrestrial reference frame, earth rotation, positioning and navigation (Dow, et al. 2008).

In this paper the IGS stations of the Indian plate and its adjacent plates have been used to estimate the overall plate motion vector of the Indian plate in relation to the adjoining plates.

\section{PREVIOUS STUDIES}

The geodynamics of the Indian plate has been studied by many researchers over the time using GPS based observations carried out at many places. These studies reveal that the Indian plate is moving with the speed of over $5 \mathrm{~cm} / \mathrm{yr}$ in the direction of $\mathrm{N} 44^{\circ} \mathrm{E}$, relative to IGS station at Bangalore and that Peninsular India is moving as a rigid plate along with the Indian plate (Jade, 2004). Malaimani, et al.(2008) analyzed 
three years of GPS data during 1995 to 1998 and found out that the IGS station at Hyderabad moves relative to Eurasian plate in the ITRF-96 reference frame with a velocity of $3.7 \mathrm{~cm} / \mathrm{yr}$ which is smaller than NUVEL-1A plate model, i.e. $4.5 \mathrm{~cm} / \mathrm{yr}$. They also found that there is no significant motion that exists between Hyderabad and Bangalore, lying $500 \mathrm{~km}$ apart in N-S direction on the Indian plate. Mahesh et al. (2012) have analyzed GPS data from 26 sites located on the Indian plate and along its boundary. By using this longer duration of data they have estimated the pole of rotation for the Indian plate, located at $51.41 \pm 0.07^{\circ} \mathrm{N}$ : $8.97 \pm 0.8^{\circ} \mathrm{E}$ and the angular velocity of the pole at $0.539 \pm 0.002^{\circ} / \mathrm{Myr}$. Their analysis suggests that the internal deformation of the Indian plate is very low $(<1-2 \mathrm{~mm} / \mathrm{yr})$ and the entire plate interior region behaves as a rigid plate. Malaimani et al. (2008) analyzed 11 years of GPS data and have estimated the baseline vectors and the rate of change of baseline lengths from HYDE to other chosen IGS stations in the sub-centimetre accuracy and also compared their pole of rotation $\left(29.44 \pm 1.2^{\circ} \mathrm{N}\right.$, $\left.13.20 \pm 7.3^{\circ} \mathrm{E}\right)$ and angular velocity of the pole $\left(0.356 \pm 0.035^{\circ} / \mathrm{Myr}\right)$ with the NUVEL-1A data $\left(24.50 \pm 1.8^{\circ} \mathrm{N}\right.$, $17.70 \pm 8.8^{\circ} \mathrm{E}$ and $\left.0.51 \pm 0.06^{\circ} / \mathrm{Myr}\right), \quad$ REVEL-2000 data $\left(28.56 \pm 14.4^{\circ} \mathrm{N}, 11.62 \pm 1.1^{\circ} \mathrm{E}\right.$ and $\left.0.357 \pm 0.033^{\circ} / \mathrm{Myr}\right)$ and combination of regional GPS and Quaternary fault slip data $\left(29.88^{\circ} \mathrm{N}, 7.50^{\circ} \mathrm{E}\right.$ and $\left.0.35^{\circ} / \mathrm{Myr}\right)$ of Holt et al. (2000).

Many researchers worked on the convergence rate of Indian plate relative to Eurasian plate. Freymuller et al.(1996) analyzed GPS data from 1991 to 1995 to estimate the motion of sites in Bangalore, in southern India, and Kathmandu, Nepal, relative to a global GPS network. Their analysis revealed the northward motion of the Indian plate and convergence between the southern Himalaya and the Indian subcontinent. They have estimated the velocities of Bangalore and Kathmandu in the ITRF-92 reference frame and matched it with the NNR-NUVEL 1A plate motion model for Indian plate motion. They observed that the India and Australian plates are moving independently and negated significant motion between Bangalore and Kathmandu during the period of analysis, even though Kathmandu is located in the hanging wall of the active Himalayan thrust system. The absence of motion of Kathmandu relative to Indian plate can be explained if the thrust system is presently locked south of the Greater Himalaya. They also found the convergence rate of the Himalayan thrust system is at the rate of $18 \pm 7 \mathrm{~mm} / \mathrm{yr}$, and has been the source of several major $\mathrm{M} \sim 8$ earthquakes.

\section{DATA USED AND METHODOLOGY}

Data from continuously operating reference GPS stations have been used to understand the tectonics and geodynamics of the Indian plate and its adjacent plates. The data of 12 IGS stations (namely IISC, HYDE, LHAZ, GUAO, KIT3, POL2, COCO, KARR, YAR2 ,SEY1, ADIS and MAL2) from 2011 to 2013 (five days of data for every three months) had been taken for processing. These belong to the Indian plate and its adjacent plates of Eurasian, Australian, Somaliyan and African plates and have been considered to understand the motion vector of the Indian plate relative to that of the other plates. On Eurasian plate, Lhasa station has been taken to measure the east-west extension of Southern Tibet (Larson, et al., 1999). The list of the IGS stations used in the study has been given in Table 1. This data has been taken from Scripps Orbital and Positioning Centre (SOPAC).

The GPS data were processed using the latest version of GAMIT/GLOBK 10.5 (Herring, 2013). This software is designed to run under any UNIX operating system. We have used this software in Red Hat Linux 6.2 version. Phase data and pseudo rage observations in rinex format are the inputs for GAMIT (Banerjee, 2002).

Table 1: Details of the IGS stations used in the study

\begin{tabular}{|l|l|c|c|l|}
\hline Site & Code & Longitude & Latitude & Plate \\
\hline Hyderabad & HYDE & 78.55 & 17.41 & Indian \\
\hline Bangalore & IISC & 77.57 & 13.02 & Indian \\
\hline Lhasa & LHAZ & 91.10 & 29.65 & Eurasian \\
\hline Urumqi & GUAO & 87.17 & 43.47 & Eurasian \\
\hline Bishkek & POL2 & 74.69 & 42.67 & Eurasian \\
\hline Kitab & KIT3 & 66.88 & 39.14 & Eurasian \\
\hline Cocos Island & COCO & 96.83 & -12.18 & Australian \\
\hline Karratha & KARR & 117.09 & -20.98 & Australian \\
\hline Dongara & YAR2 & 115.34 & -29.04 & Australian \\
\hline La Misere & SEY1 & 55.47 & -4.67 & Somaliyan \\
\hline Addis Ababa & ADIS & 38.76 & 9.03 & African \\
\hline Malindi & MAL2 & 40.19 & -2.99 & African \\
\hline
\end{tabular}

Automatic data cleaning (King and Bock 2013) has been done using GAMIT to remove the all significant noise (for example cycle slips) by fitting the least square solution with double difference equations (Mansion, et.al 2000). Daily ambiguities were fixed to nearly $90 \%$ which assures good editing and got the noise free solution.

GLOBK is a Kalman filter, that combines all these GAMIT solutions and gives the time series plots and velocity vectors for the stations. Along with GLORG, GLOBK stacks all the $\mathrm{H}$-files and will give the loose constrain solution. All the station positions and their rates were estimated in ITRF-2008 (Altamimi, et al., 2011), Indian reference frame, relative to IISC station, relative to KARR station, and relative to POL2 station by stabilizing the sites using GLOBK, GLORG (Herring, 2013). In GLOBK, data of individual days of each year was combined into a seasonal estimate of position at each site. These seasonal estimates were then combined in a weighted multi-year GLOBK/GLORG solution to determine the velocity parameters at each of the sites in the ITRF-2008 frame (Mansion, et al. 2000). The relative movements of stations were estimated by a fixing process in the analysis. This has been done to stations on all the plates except those on African and Somaliyan plates.

\section{RESULTS AND DISCUSSIONS}

The estimated velocities of IGS stations on the Indian plate and its adjacent plates in the ITRF-2008 frame, Indian reference frame and also relative to IISC station (Indian plate), KARR station (Karratha, Australian plate) and POL2 station (Bishkek, Eurasian plate) are given in Table 2.

To estimate the movement of one IGS station relative to other IGS stations, a few IGS stations on the Indian plate and its adjacent plates have been fixed during the processing stage. The Indian plate motion vector has been estimated as $54.25 \pm$ $0.73 \mathrm{~mm} / \mathrm{yr}$, towards $\mathrm{N} 40^{\circ}$ in the ITRF-2008 reference frame. The movement vectors of other stations relative IISC have also been calculated as given in table 2 . 
Table 2: Estimated horizontal velocities of IGS stations (mm/yr)

\begin{tabular}{|c|r|r|r|r|r|}
\hline Station & $\begin{array}{c}\text { ITRF- } \\
\mathbf{2 0 0 8}\end{array}$ & $\begin{array}{c}\text { Indian } \\
\text { Ref. }\end{array}$ & $\begin{array}{c}\text { IISC } \\
\text { Fixed }\end{array}$ & $\begin{array}{c}\text { Pol2 } \\
\text { Fixed }\end{array}$ & $\begin{array}{c}\text { Karr } \\
\text { Fixed }\end{array}$ \\
\hline HYDE & 53.6 & 2 & 1.25 & 35 & 19.3 \\
\hline IISC & 54.9 & 2 & 0.27 & 36 & 16.5 \\
\hline LHAZ & 49.1 & 20 & 25 & 25 & 45.6 \\
\hline GUAO & 33.6 & 28 & 33 & 7 & 51.2 \\
\hline POL2 & 28.3 & 28 & 31 & 2 & 45 \\
\hline KIT3 & 28.1 & 27 & 28 & 3 & 40 \\
\hline COCO & 69.7 & 22 & 16 & 63 & 4 \\
\hline KARR & 70.4 & 28 & 20 & 71 & 0.1 \\
\hline YAR2 & 70.3 & 28 & 19 & 72 & 0.8 \\
\hline SEY1 & 24.9 & 29 & 30 & 2 & 20 \\
\hline ADIS & 30.4 & 16 & 17 & 4 & 17.2 \\
\hline MAL2 & 29.8 & 21 & 23 & 4 & 18.5 \\
\hline
\end{tabular}

The IISC station (Bangalore) is moving with the speed of $54.9 \pm$ $0.74 \mathrm{~mm} / \mathrm{yr}$ in the $\mathrm{N} 40^{\circ} \mathrm{E}$ direction in the ITRF-2008 reference frame. Because of this $\mathrm{NE}$ movement and also due to the differential rate of movement of the Eurassian plate with respect to the Indian Plate, there is strain accumulation across the IndoEurassian collision zone, which is propagating through the series of regional structures (MCT/MBT/HFT) south of the presently inactive Indus Suture zone (the actual collision zone). The central seismic gap represented between the Kangra (1905) and Bihar (1934) earthquakes is a potential zone where there are chances of future occurrence of earthquakes. After 1255 earthquake there is no significant earthquake in this gap, so systematic observations are required along these thrust systems to track the movement and strain accumulation.

Figure 1 and figure 2 are showing the velocities and directions of the Indian IGS sites and those on adjacent plates in the ITRF-2008 frame and relative to IISC Station, respectively. Figure 1 shows that the stations are moving in NE direction. The stations on the Australian plate (KARR, YAR2, COCO) are showing velocities greater than those from other plates (approximately $70 \mathrm{~mm} / \mathrm{yr}$.) $\mathrm{We}$ got high rate of movement for the COCO station relative to the other IGS stations agreed by Gordon and DeMets (1989) and Kreemer, et al. (2003), Ravi Kumar, et al. (2008). Our estimated plate velocity vectors match with the NUVEL-1A plate model predictions (De Mets et. al., 1994). No co-seismic displacement corrections were applied to this data, because of no significant earthquake happened during the time span of the data used.

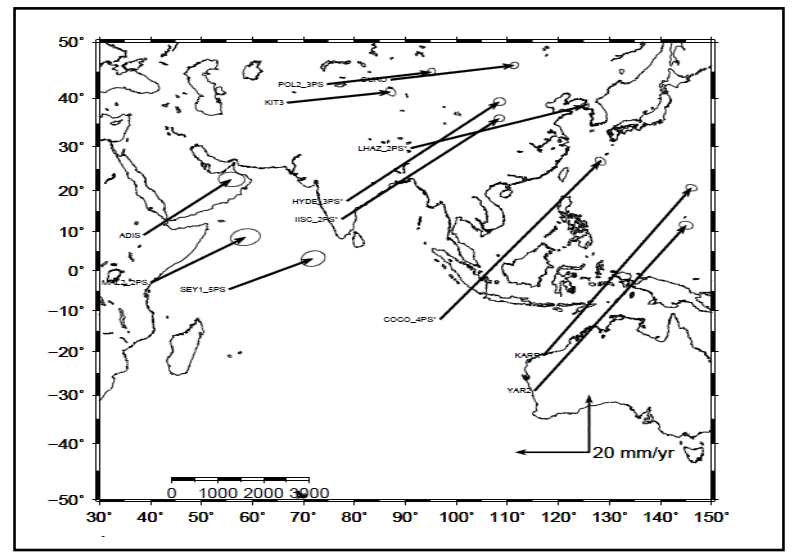

Fig. 1. Velocity vectors in ITRF-2008
Figure 2 shows the velocity vectors of IGS sites on Indian, Eurasian, Australian, Pacific and Somaliyan plates with respect to IISC station. When the IISC (Bangalore) station has been fixed, the sites on Eurasian plate show south easterly movement, with velocity ranging from 25 to $33 \mathrm{~mm} /$ year. At the same time the IGS sites on Australian plate show movement towards North with average velocity of about 20 $\mathrm{mm} /$ year and the sites on African plate are moving in westward direction with average velocity of $18 \mathrm{~mm} /$ year. The movement of the IGS sites in India in the Indian reference frame and relative to IISC station are not very significant. (Table 2, Figure 2). And we also confirm that southern Peninsular India is moving as a rigid plate with the velocity of Indian plate (Jade, 2004). The relative motion of the Indian plate with respect to the Bishkek station (POL2) on Eurassian Plate has been found to be about $35 \mathrm{~mm} /$ year in the NNE direction. At the same time the Lhasa station on the Eurassian Plate close to the Indian Plate is also showing a velocity vector of about $25 \mathrm{~mm} /$ year NE direction. Similarly, the stations on the Australian Plate show an average rate of 68 $\mathrm{mm} /$ year in NE direction with respect to the Bishkek station on Eurassian Plate.

Relative to the Karratha station on the Australian Plate, the Indian Plate's stations give a velocity of about $18 \mathrm{~mm} / \mathrm{year}$ in the ESE direction while the stations on the Eurassian plate shows an average of $46 \mathrm{~mm} /$ year in the SE direction.

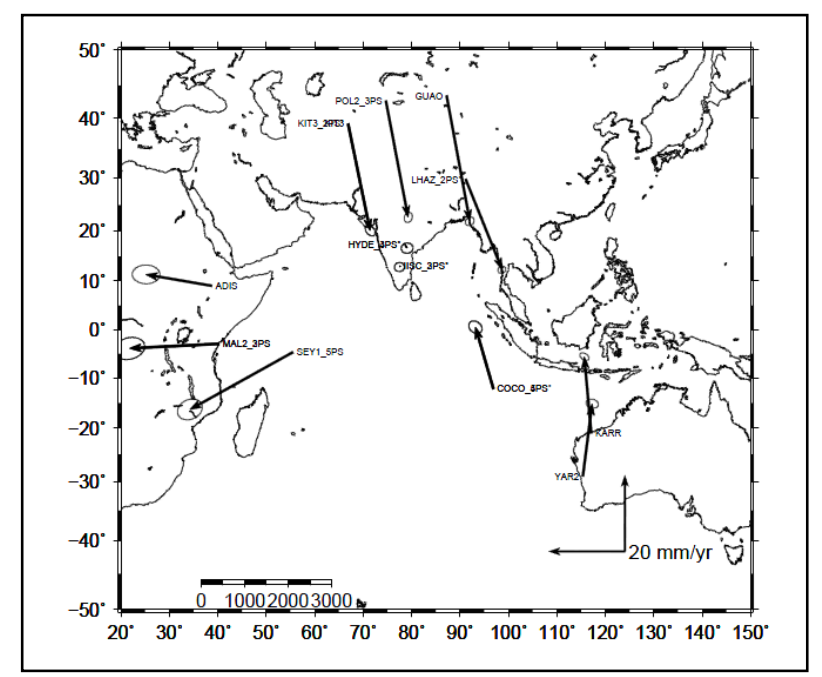

Fig. 2. Velocity vectors relative to IISC Station

\section{CONCLUSIONS}

Precise IGS data from 2011 to 2013 have been analyzed to find the Indian plate motion. Alongwith the Indian IGS sites we have analyzed a few IGS sites on adjacent plates of India. The Indian plate's velocity has been estimated as about 5.5 $\mathrm{cm} / \mathrm{yr}$ in the ITRF-2008 reference frame and about $2 \mathrm{~mm} / \mathrm{yr}$ in the Indian reference frame. Velocity of Eurasian , African, Somaliyan and Australian Plates have also been calculated. Among these Plates Australian Plate showed the fastest rate of movement followed by the Indian plate. The differential movement of the Indian Plate against the Eurassian plate results in strain accumulation across the Himalaya which accommodates crustal shortening. The stations in the Eurassian plate are moving with velocity ranging from 25 to $33 \mathrm{~mm} /$ year in the SE direction relative to fixed IISC (Bangalore) station, resulting in compressional interaction 
with the Indian plate. This study reveals and confirms to the previous studies that the Indian-Eurassian-Australian Plates are moving at different relative velocities leading to compressional regimes at their margins leading to seismicity in these zones.

\section{ACKNOWLEDGEMENTS}

The authors are thankful to Dr. V. K. Dadhwal, Director, NRSC, for the motivation to carry out this work. Dr. P. G. Diwakar, Deputy Director, NRSC, has been thanked for his guidance. Dr. Herring and Dr. Bob King (MIT), Dr. Vineeth K Gahaulat and Dr. Joshi Catherine (NGRI, Hyderabad) have extended their help regarding the GAMIT/GLOBK processing and are sincerely thanked. The financial support to the first author by ISRO is acknowledged.

\section{REFERENCES}

Altamimi, Z., Collilieux, X. and Métivier, L., 2011. ITRF-2008: an improved solution of the international terrestrial reference frame. J Geod (2011) 85:457-473, DOI 10.1007/s00190-11-04444.

Banerjee, P. and Bürgmann, R., 2002. Convergence across the northwest Himalaya from GPS measurements, Geophys Res Lett., VOL. 29, NO. 13, 1652, 10.1029/2002GL015184, 2002.

Beutler, G., Mervart, L. and Verdun, A., 2005. Methods of celestial mechanics, Vol 1, $32 \mathrm{p}$.

Bevis, M. and Gross, R., 2011. "Commission 3 - Geodynamics and Earth Rotation," Report of the International Association of Geodesy 2007-2011 - Travaux de l'Association Internationale de Géodésie 2007-2011

DeMets, C., Gordon, R.G., Argus, D. and Stein, S., 1994. Effect of recent revisions to the geomagnetic reversal time scale on estimates of current plate motions, Geophys. Res. Lett., 21, 21912194, 1994

Dow, J.M., Neilan , R.E., and Rizos, C., 2009. The International GNSS Service in a changing landscape of Global Navigation Satellite Systems, Journal of Geodynamics (2009) 83:191-198 DOI 10.1007/s00190-008-0300-3.

Freymuller, J., Bilham, R., Bürgmann, R., Larson K.M., Paul, J., Jade, S. and Gaur, V., 1996. Global positioning system measurements of Indian plate motion and convergence across the Lesser Himalaya, Geophys Res Lett., VOL. 23, NO. 22, PAGES 3107-3110, NOVEMBER 1, 1996

Gordon, R.G., and DeMets, C., 1989. Present -day motion along the Owen fracture zone and Dalrymple trough in the Arabian sea, J.Geophys.Res., 94, 5560-5570.

Herring, T., Global Kalman filter VLBI and GPS analysis program ,(v 5.23) Massachusetts Institute of Technology, 2013.

Holt, W.E., Chamot-Rooke,N., Le Pichon, X.,. Haines, A.J., Shen-Tu, B. \& Ren, J., 2000. Velocity field in Asia inferred from Quaternary fault slip rates and Global Positioning System observations, J. Geophy .Res., 105, 19, 185-19, 209.
King, R. W. and Y. Bock, Documentation for the GAMIT GPS analysis software (v10.5), Massachusetts Institute of Technology, 2013.

Kreemer, C., Holt, W.E. and Haines, A.J., 2003. An integrated global model of present-day plate motions and plate boundary deformation, Geophysical Jour. International., 154, 8-34.

Larson, K.M., Bürgmann, R., Bilham, R. and Freymuller, J.T., 1999. JOURNAL OF GEOPHYSICAL RESEARCH , VOL. 104, NO. B1, PAGES 1077-1093, JANUARY 10, 1999.

Mahesh, P., et al. 2012. Gondwana Research, Rigid Indian plate: Constraints from GPS measurements, Gondwana res.Lett., 22(2012), 1068-1072.

Malaimani, E.C., Campbell, J., Barbara, G., Holger, K., and Smaritschnik, S., 2000. Indian plate kinematic studies by GPS-geodesy, Earth Planets Space, Lett., 52, 741-745, 2000.

Malaimani, E.C., Ravi Kumar, N., Akilan, A. and Abilash, K., 2008. GPS-Geodesy with GNSS Receivers for Indian Plate Kinematics studies with the recent plate velocities estimated from GNSS data, J. Ind. Geophys. Union ( July 2008 ), Vol.12, No.3, pp.109-114.

Mansion, R., Coleman, R., Morgan, P. and King, M., 2000. Ice velocities of Lambert Glacier from static GPS observations, Earth Planets Space, 52, 1031-1036, 2000.

Ravi Kumar, N., Malaimani, E.C., Akilan, A. and Abilash, K., 2008. 10 years of Continuous GPS measurements for geodetic tying of Antarctica and India for geodynamical and strain accumulation studies in the south of Indian Peninsula, $J$. Ind. Geophys. Union (July 2008), Vol.12, No.3, pp.115-122.

Sridevi, J., 2004. Estimates of plate velocity and crustal deformation in the Indian subcontinent using GPS geodesy, CURRENT SCIENCE, VOL. 86. NO.10. 25 MAY 2004.

Sridevi, J., Bhatt, B.C., Yang, Z., Bendick, R., Gaur, V.K., Molnar, P., Anand, M.B. and Kumar, D., 2004. GPS measurements from the Ladakh Himalaya, India: Preliminary tests of plate like or continuous deformation in Tibet, Geological Society of America Bulletin, doi: 10.1130/B25357.1 v. 116 no. 11-12 p. 1385-1391. 